\title{
CORA - a dedicated device for carbon dioxide monitoring in cave environments
}

\author{
Marc Luetscher ${ }^{1}$ and Felix Ziegler ${ }^{2}$
}

\begin{abstract}
:
Luetscher M., Ziegler F. 2012. CORA-a dedicated device for carbon dioxide monitoring in cave environments. International Journal of Speleology, 41(2), 273-281. Tampa, FL (USA). ISSN 0392-6672. http://dx.doi.org/10.5038/1827-806X.41.2.13

High resolution time-series of cave $\mathrm{CO}_{2}$ fluctuations are increasingly demanded to quantify calcite precipitation processes. CORA, an energy-efficient NDIR-device, has been specifically developed for the long-term monitoring of carbon dioxide in remote cave environments. To allow comparison between different cave sites, changes in air pressure and temperature are compensated for using dedicated probes. Laboratory experiments demonstrate that CORA's precision is adapted to the analysis of spatially and temporally variable $\mathrm{CO}_{2}$ regimes and therefore suitable for a large number of applications. Data obtained with 12 independently calibrated instruments are reproducible within 3\% $(1 \sigma)$. The two-point calibration function is validated using certified reference gases for an overall accuracy determined at $\pm 50 \mathrm{ppmv}$, resp. $\leq \pm 3 \%$. Although no significant drift was observed during the test phase a periodic recalibration is recommended. Initial results from field studies show that continuous monitoring over a full annual cycle is possible at 4 hour intervals without specific maintenance.
\end{abstract}

Keywords: cave; carbon dioxide $\left(\mathrm{CO}_{2}\right)$; monitoring; climate; speleothem Received 13 January 2012; Revised 2 April 2012; Accepted 14 May 2012

\section{INTRODUCTION}

Carbon dioxide is a key component for karstification, namely the dissolution and precipitation of $\mathrm{CaCO}_{3}$ which affects most carbonate rocks. The initiation and development of karst conduits results in complex drainage patterns controlling the subsurface hydrology and meteorology (Ford \& Williams, 2007). Because of the transient transport processes and spatial heterogeneity inherent to these karst systems, the subsurface $\mathrm{PCO}_{2}$ is typically increased as compared to the external atmosphere and may vary both in space and time (e.g., Bourges et al., 2001; Fernandez-Cortes et al., 2006, 2009; Baldini et al., 2006).

Previous studies have identified three potential sources for carbon dioxide in caves (James, 1977): 1) soil respiration; 2) oxidation of organics transported into the cave and, 3) a deep-seated, hydrothermal origin. Depending on production rates and ventilation regimes cave air $\mathrm{CO}_{2}$ concentrations may vary by several orders of magnitude. In vadose cave environments, $\mathrm{CO}_{2}$ concentrations typically range between values close to the external atmosphere and about 4\% (e.g. Troester \& White, 1984; Ek \&

${ }^{1}$ Institute of Geology and Palaeontology, University of Innsbruck, Innrain 52 A-6020 Innsbruck (marc.luetscher@uibk.ac.at)

${ }^{2}$ Ingenieurbüro Ziegler, Schönau, CH - 8825 Hütten (fz@zie.ch)
Gewelt, 1985; Bourges et al., 2006; Batiot-Guilhe et al., 2007; Liñán et al., 2008) but extreme values of up to $18 \%$ have occasionally been reported (Halliday, 1984). Studying cave $\mathrm{PCO}_{2}$ fluctuations is therefore fundamental to quantify dissolution and precipitation rates of calcium carbonate and assess the contribution of karst processes onto the global carbon cycle. Moreover, elevated cave air $\mathrm{CO}_{2}$ concentrations may be an indicator of pollution in a cave or its catchment area (e.g. Debosz et al., 2002), which may eventually affect groundwater resources.

The interest in the spatial distribution and the temporal evolution of cave $\mathrm{PCO}_{2}$ has significantly risen with the successful use of speleothems as terrestrial paleoclimate archives (e.g. review by Fairchild et al., 2006). Banner et al. (2007) demonstrated that changes in the cave $\mathrm{PCO}_{2}$ modify stalagmite growth rates and thus impinge on paleoclimate proxies, including stable isotopes (Spötl et al., 2005; Mattey et al., 2008, Frisia et al., 2011) and trace elements (Treble, 2005; Johnson, 2006; Wong et al., 2011). So far, cave $\mathrm{CO}_{2}$ data were however, often limited to discontinuous measurements and only during the recent years, with the onset of non-dispersive infrared (NDIR) measurement techniques, continuous monitoring of cave $\mathrm{CO}_{2}$ has become more frequent (e.g. Baldini et al., 2008; Kowalcz \& Froelich, 2009; Sherwin \& Baldini, 2011). 
Unfortunately, commercially available instruments rarely suit the specific requirements for cave monitoring and many systems face severe limitations due to power supply and/or electronics failure due to elevated condensation rates. In absence of coupled probes, correction for pressure and temperature changes is often hindered, making a comparison between monitoring sites difficult. Here we present a new energy-efficient NDIR-device for the long-term monitoring of $\mathrm{CO}_{2}$ concentrations in cave environments. This hand-held instrument was specifically developed for exigent monitoring conditions (e.g. no grid supply, difficult access, low temperature, high humidity, muddy conditions) and successfully tested for several months in an alpine cave. Versions of this instrument are currently operating at cave sites across Europe (Bärenhöhle, Katerloch, Obir, and Spannagelhöhle, Austria; Milchbachsystem and Milandre cave, Switzerland, and Conturines cave, Italy) as well as in Australia (Wombeyan cavern).

\section{NDIR GAS ANALYSIS - METHODOLOGICAL BACKGROUND}

It has been empirically demonstrated that various gases absorb radiation in the infrared portion of the electromagnetic spectrum due to intramolecular vibrations. According to the wavelength of the incident radiation (typically between 2 and $20 \mu \mathrm{m}$ ) and depending on the chemical bond structure of the target molecules, a series of absorption peaks will be observed. The non-dispersive measurement technique uses fixed band-pass filters to identify characteristic absorption lines over a selected wavelength range (e.g. Stuart, 1996). The intensity of IR light reaching the detector is inversely related to the concentration of the target gas in the sample chamber. Following the Beer-Lambert law (Eq. 1), the concentration of the target gas is given by:

$$
\mathrm{I}=\mathrm{I}_{0} \mathrm{e}^{-\alpha \mathrm{LC}}
$$

where I is the intensity measured in the target gas [V]; Io is the intensity measured in absence of target gas (zero gas) [V]; a is a gas-specific absorption coefficient $\left[\mathrm{m}^{3} \cdot \mathrm{mol}^{-1} \cdot \mathrm{cm}^{-1}\right] ; \mathrm{L}$ is the length of the optical path $[\mathrm{cm}]$ and $\mathrm{C}$ is the concentration of the target gas.

This idealised expression faces issues related to the mechanical and optical alignment of the sensor components, lamp intensities and spectral output. To compensate for non-linearity effects Equation (1) is modified by introducing two empirical parameters (e2v, 2007):

$$
\mathrm{I}=\mathrm{I}_{0} \exp \left(-\mathrm{aC}^{\mathrm{n}}\right)
$$

where $\mathrm{a}$ and $\mathrm{n}$ are specific to a particular sensor design and determined for individual concentration ranges of a given target gas.

The linearization coefficients $a$ and $n$, which can be determined empirically from measurements in reference gases at different concentrations $(e 2 v$, 2007) are typically provided by the manufacturer. Using a dual channel NDIR sensor allows comparing the detected signal with a reference signal filtered at a band width displaying no absorption lines for the specified gas. The change in output voltage measured in the presence of the target gas provides the normalized absorbance (Abs):

$$
\text { Abs }=1-\text { Act } /(\text { Zero } * \text { Ref })
$$

where Act $=$ active signal; Ref $=$ reference signal; Zero $=$ Act $/$ Ref in zero gas.

Combining Equation (2) and (3) and introducing a gas span accounting for the proportion of absorbing radiation gives:

$$
1-\text { Act } /(\text { Zero } * \text { Ref })=\operatorname{Span}\left(1-\exp \left(-\mathrm{aC}^{\mathrm{n}}\right)\right)
$$

From equation (4), we derive the target gas concentration $(\mathrm{C})$ :

$$
C=\left[\frac{\ln \left(1-\frac{A b s}{S p a n}\right)}{-a}\right]^{\frac{1}{n}}
$$

Changes in the ambient temperature and pressure can be compensated for by using the ideal gas law, providing the instrument is equipped with independent temperature and pressure probes. Self-heating effects due to the light source must be compensated by introducing a linear correction for Abs and Span using a separate temperature sensor mounted close to the gas sensor. For further details the reader should consult the manufacturers' application notes (e.g. e2v, 2007; Alphasense, 2009).

\section{CORA - A CO 2 RECORDING APPARATUS}

The CORA ${ }^{1^{*}}$ monitoring device comprises a $\mathrm{CO}_{2}$, a pressure, and a temperature probe (Table 1). Recorded data are stored on a 32 Mbit internal memory and can be transferred to an external SD-card peripheral or downloaded onto a notebook via a RS485 serial port. Thanks to its low-power consumption the device allows monitoring at 4 hour intervals for at least one full year without maintenance. Data exchange with the instrument software is achieved through a Membrane Keypad allowing programming the measurement time interval (5 min to $48 \mathrm{~h}$ ), to start monitoring sequences and to download data.

CORA was specifically developed to resist dirt and water splashes (IP52) typical of cave environments. The device consists of a $15 \times 9 \times 5 \mathrm{~cm}$ handheld apparatus with a digital display. Six internal alkaline AA cells $(9 \mathrm{~V} ; 3.4 \mathrm{Ah})$ supply sufficient energy for one month autonomy. The instrument weighs $590 \mathrm{~g}$ and is packed in a waterproofed Otter Case for transport (Fig. 1). For monitoring periods exceeding one month, the instrument can be coupled to an external battery pack (12V; 22 Ah; Fig. 2). The total weight of CORA including external batteries is slightly less than $3 \mathrm{~kg}$.

\footnotetext{
${ }^{1}$ Cora, also known as Persephone, reigned the underworld together with Hades in the Greek mythology.
} 


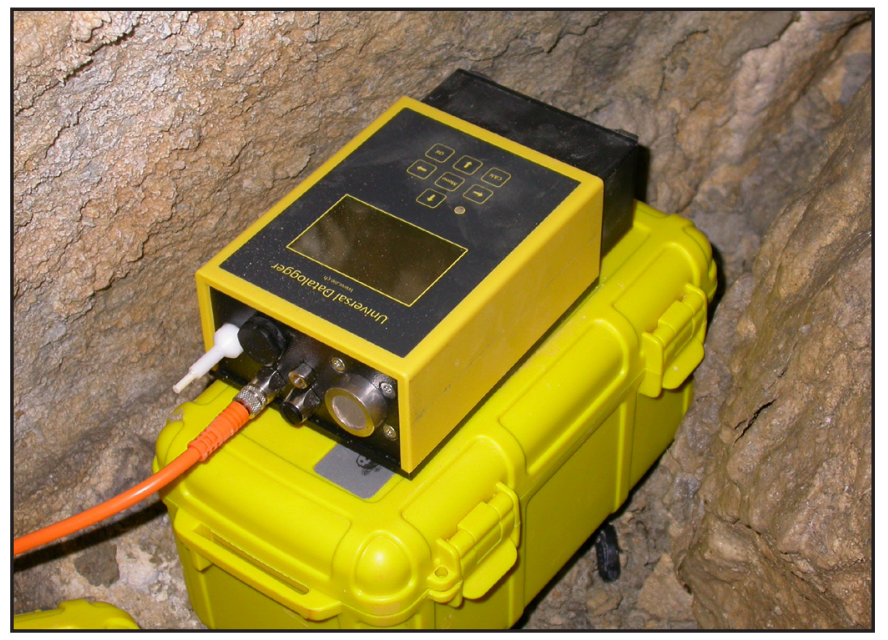

Fig. 1. The CORA device used for monitoring $\mathrm{CO}_{2}$ concentrations in cave air. The yellow box underneath the device holds eight $1.5 \mathrm{~V}$ batteries ( $\mathrm{D}$ cells).

\section{User interface}

CORA's display provides information about the instrument status and the last recorded measurement. Navigation is achieved via the membrane keypad using up and down arrows combined with "OK" and "Cancel" touches. The software menu is structured into six topics each comprising a list of relevant options: 1) measurement, 2) time interval, 3) export data, 4) settings, 5) switch off, and 6) info.

The user can choose between performing a single measurement and starting a monitoring period. The measurement time interval can be defined separately for the carbon dioxide and temperature/pressure. This option allows differentiated monitoring strategies taking into account the higher power consumption of the $\mathrm{CO}_{2}$ sensor, eg. $4 \mathrm{~h}$ for the carbon dioxide but 10 min for the other two parameters.

The settings allow selecting different display characteristics, including the contrast and backlight intensity. The instrument's date is defined manually to account for monitoring projects in different time zones. The user has also the opportunity to choose between three different languages (English, German and French); further languages will be added in the future.

The calibration menu is password-protected and an administrator can change the parameters

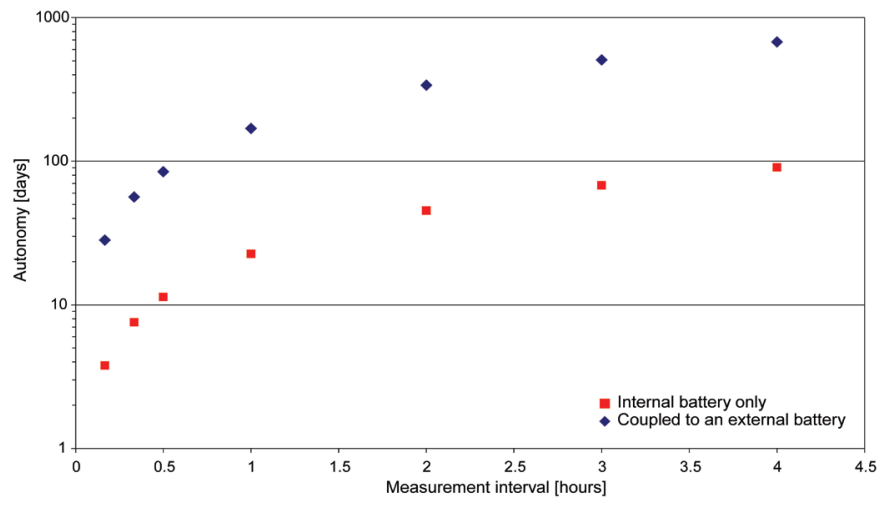

Fig. 2. Expected power autonomy of CORA according to the measured time interval. The values represent a conservative estimate valid for cold alpine cave environments.

defining the $\mathrm{CO}_{2}$ calibration curve including empirical determinations of the linearization coefficients and calibration parameters for the temperature and pressure probes.

\section{Technical - Sensor(s) - Electronics}

Changes in the atmospheric $\mathrm{PCO}_{2}$ are measured with an e2v dual channel NDIR sensor by comparing the output signal of the detector filtered to a $\mathrm{CO}_{2}$ absorption band centred at $4.2 \mu \mathrm{m}$ with a reference signal $(\lambda=\sim 4.0 \mu \mathrm{m})$. The IR source is provided by a tungsten filament hosted in a glass envelope while the air sample to be analysed enters the optical cell through a particulate filter by molecular diffusion $(\mathrm{e} 2 \mathrm{v}, 2008)$. The measured signal is proportional to the molecular density of $\mathrm{CO}_{2}$ present in the ambient air. Compensation of temperature and light source drifts is achieved through a reference channel warranting the long-term stability of the output signal (e2v, 2008).

CORA relies on a $6 \mathrm{~V}$ DC power supply which is switched on at regular time intervals for single measurements. To offset thermal background signals due to changes in light levels the IR source is modulated at $2 \mathrm{~Hz}$. The resulting signal measured at the pyroelectric detector is sinusoidal. The peakto-peak AC voltage is proportional to the incident IR allowing for synchronous detection techniques. Every $\mathrm{CO}_{2}$ measurement requires typically $50 \mathrm{~mA}$ over an

Table 1. CORA sensor specifications

\begin{tabular}{llll}
\hline Sensor & NDIR-CO & Temperature & Air Pressure \\
Manufacture & $\mathrm{e} 2 \mathrm{v}$ & IST AG & Freescale Semiconductor \\
model & $\mathrm{IR} 11 \mathrm{GJ}$ & $\mathrm{Pt} 1000 \mathrm{Class} \mathrm{A}$ & $\mathrm{MPXH} 6115 \mathrm{~A} 6 \mathrm{U}$ \\
Power requirement & $9-12 \mathrm{~V}, 80 \mathrm{~mA}$ & $0.3-2 \mathrm{~mA}$ & $3 \mathrm{~V}, 4 \mathrm{~mA}$ \\
Measurement range & $0-2 \% \mathrm{vol} . \mathrm{CO}_{2}$ & $-50-+150^{\circ} \mathrm{C}$ & $15-115 \mathrm{kPa}$ \\
Response time (signal averaging) & $180 \mathrm{sec}$ & $\mathrm{ca} .20 \mathrm{sec}$ & $1 \mathrm{~ms}$ \\
Warm-up time & $90 \mathrm{sec}$ & - & $20 \mathrm{~ms}$ \\
Accuracy & $\pm 3 \%$ of reading & $\pm 0.2^{\circ} \mathrm{C}$ & $\pm 1.5 \%$ of range \\
Long-term drift * & $0.05 \%$ vol. $/ \mathrm{month}$ & $0.04 \% / 1000 \mathrm{~h}$ & $\pm 0.25 \% / 1000 \mathrm{cycles}$ \\
\hline
\end{tabular}

* according to manufactures notes 
Table 2. Reproducibility of $\mathrm{CO}_{2}$ measurements using 12 different CORA devices and a certified reference gas $\left(7384 \pm 147\right.$ ppmv $\left.v_{\text {satp }}\right)$; n.d.: not determined.

\section{CORA \# Normalised absorbance Calibrated $\left[\mathrm{CO}_{2}\right] \quad$ Number of meas.}

$\begin{array}{lcl}2 & 0.230060 \pm & 0.000839 \\ 3 & 0.239571 \pm & 0.001962 \\ 4 & 0.219034 \pm & 0.003982 \\ 10 & 0.125561 \pm & 0.001061 \\ 11 & 0.097857 \pm & 0.000078 \\ 12 & \text { n.d. } & \text { n.d. } \\ 13 & 0.104523 \pm & 0.000437 \\ 14 & \text { n.d. } & \text { n.d. } \\ 21 & 0.301808 \pm & 0.002277 \\ 22 & 0.298984 \pm 0.002963 \\ 23 & 0.305982 \pm 0.002736 \\ 24 & 0.302495 \pm 0.000931 \\ 25 & 0.309169 \pm 0.002164 \\ 26 & 0.324852 \pm 0.001300\end{array}$

$\begin{array}{rrr}7267 \pm 49 & 3 \\ 7494 \pm 174 & 8 \\ 7248 \pm 78 & 2 \\ 7442 \pm 122 & 9 \\ 7644 \pm & \pm 35 & 3 \\ \text { n.d. } & \text { n.d. } & \\ 7766 \pm 105 & 6 \\ \text { n.d. } & \text { n.d. } & \\ 7481 \pm 16 & 3 \\ 7549 \pm 113 & 3 \\ 7488 \pm 77 & 2 \\ 7356 \pm 15 & \pm \\ 7515 \pm 101 & 3 \\ 7842 \pm 42 & 3\end{array}$

$7508 \pm 179$ ppmv satp

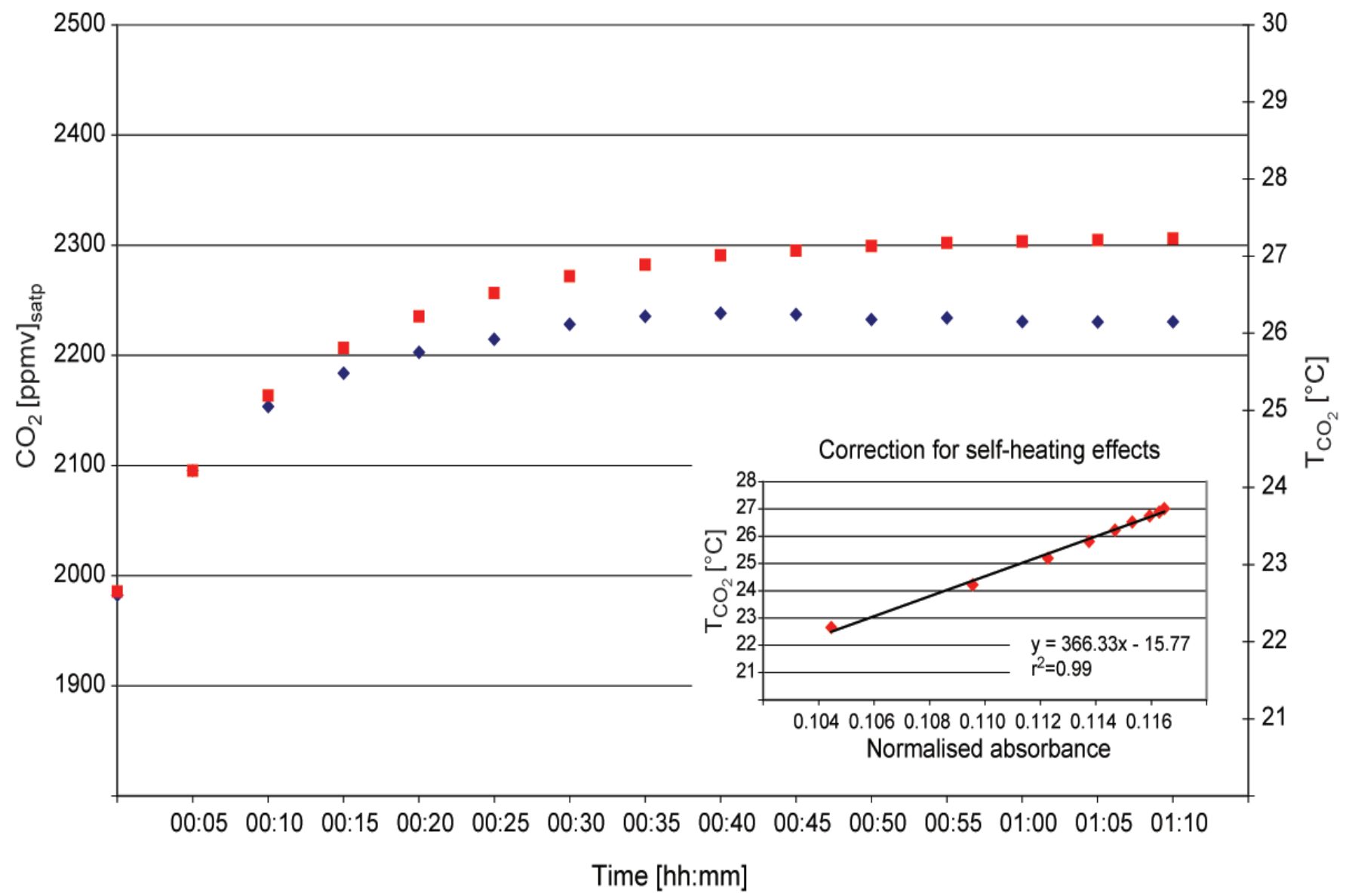

Fig. 3. Temperature dependency of $\mathrm{CO}_{2}$ readings at 5 min intervals and constant $\mathrm{PCO}_{2}$. Blue diamonds: measured $\left[\mathrm{CO}_{2}\right]$ values; red squares: temperature of the NDIR sensor $\left(\mathrm{TCO}_{2}\right)$. The measurement at $\mathrm{t}_{0}$ corresponds to the actual calibrated measurement. Self-heating associated to short measurement intervals can be corrected for (inset). 
acquisition window lasting $270 \mathrm{~s}$. During the first $90 \mathrm{~s}$ the sensor is preheated and the data are disregarded. Measurements performed during the following $180 \mathrm{~s}$ are averaged to the final result using a low-pass filter. Digital signal processing provides the temperatureand pressure-corrected $\mathrm{CO}_{2}$ mole fraction in ambient air $[\mu \mathrm{mole} / \mathrm{mole}]$.

\section{AIR TEMPERATURE AND PRESSURE COMPENSATION}

To allow a comparison of carbon dioxide measurements between different cave sites as well as in large cave systems showing a range in air pressure and temperature, the measured concentration of $\mathrm{CO}_{2}$ is compensated for atmospheric changes:

$$
\left[\mathrm{CO}_{2}\right]_{\text {satp }}=\left[\mathrm{CO}_{2}\right]_{\text {meas. }} \frac{1013.25 * T_{\text {meas. }}}{288.15 * P_{\text {meas. }}}
$$

where $\left[\mathrm{CO}_{2}\right]_{\text {satp }}$ is the $\mathrm{CO}_{2}$ molar concentration [ppm] in the standard atmosphere at constant temperature and pressure (satp; $25^{\circ} \mathrm{C}, 1013.25 \mathrm{hPa}$ ); $\left[\mathrm{CO}_{2}\right]_{\text {meas. }}$ is the measured $\mathrm{CO}_{2}$ molar concentration; $\mathrm{T}_{\text {meas }}$ is the cave air temperature $[\mathrm{K}]$ and $\mathrm{P}_{\text {meas }}$ is the barometric pressure $[\mathrm{hPa}]$.

\section{TEMPERATURE DEPENDENCY - SELF-HEATING}

Temperature effects due to self-heating of the NDIR sensor are compensated for at each acquisition window using an internal thermistor. As full thermal equilibrium of the sensor is only reached after ca.
30 min (Fig. 3) analysing transient thermal regimes may require an additional correction to ensure a high accuracy. This may be particularly relevant in the entrance zone of warm cave systems where the heat exchange between the sensor and the subsurface atmosphere is slower than in colder cave environments. Overall, it is recommended to keep the measurement interval at minimum 15 minutes.

\section{CORA PERFORMANCES}

\section{Precision and long-term drift}

The short-term precision of CORA measurements was tested at $2 \mathrm{~s}$ intervals over $900 \mathrm{~s}$. After correcting for temperature effects due to sensor heating, the relative standard deviation of the normalised absorbance measured in air at constant $\mathrm{PCO}_{2}$ (i.e. $100 \% \mathrm{~N}_{2}$ ) reaches $\pm 0.02 \%$. Similar results (i.e. $\pm 0.03 \%$ ) were obtained from 153 individual measurements acquired over $77 \mathrm{~h}$ at 20 min intervals (CORA \#13).

The long-term precision of the instrument was determined at daily intervals over a period of 8 months with a 2000 ppmv $\mathrm{CO}_{2}$ reference gas (1832 $\pm 40 \mathrm{ppm}$ satp) involving a total of 138 individual measurements (CORA \#2). Results shown in Fig. 4 suggest no significant drift during the observation period at an overall precision of the normalised absorbance of $\pm 0.1 \%$ ( 1 sigma). In terms of the $\mathrm{CO}_{2}$ concentration the latter corresponds to an absolute precision of $1829 \pm 29$ ppmv, i.e. $1.6 \%$ of the measured value. This five times larger variance as compared to the short-term precision is primarily attributed to secondary effects associated with fluctuations of the battery voltage.

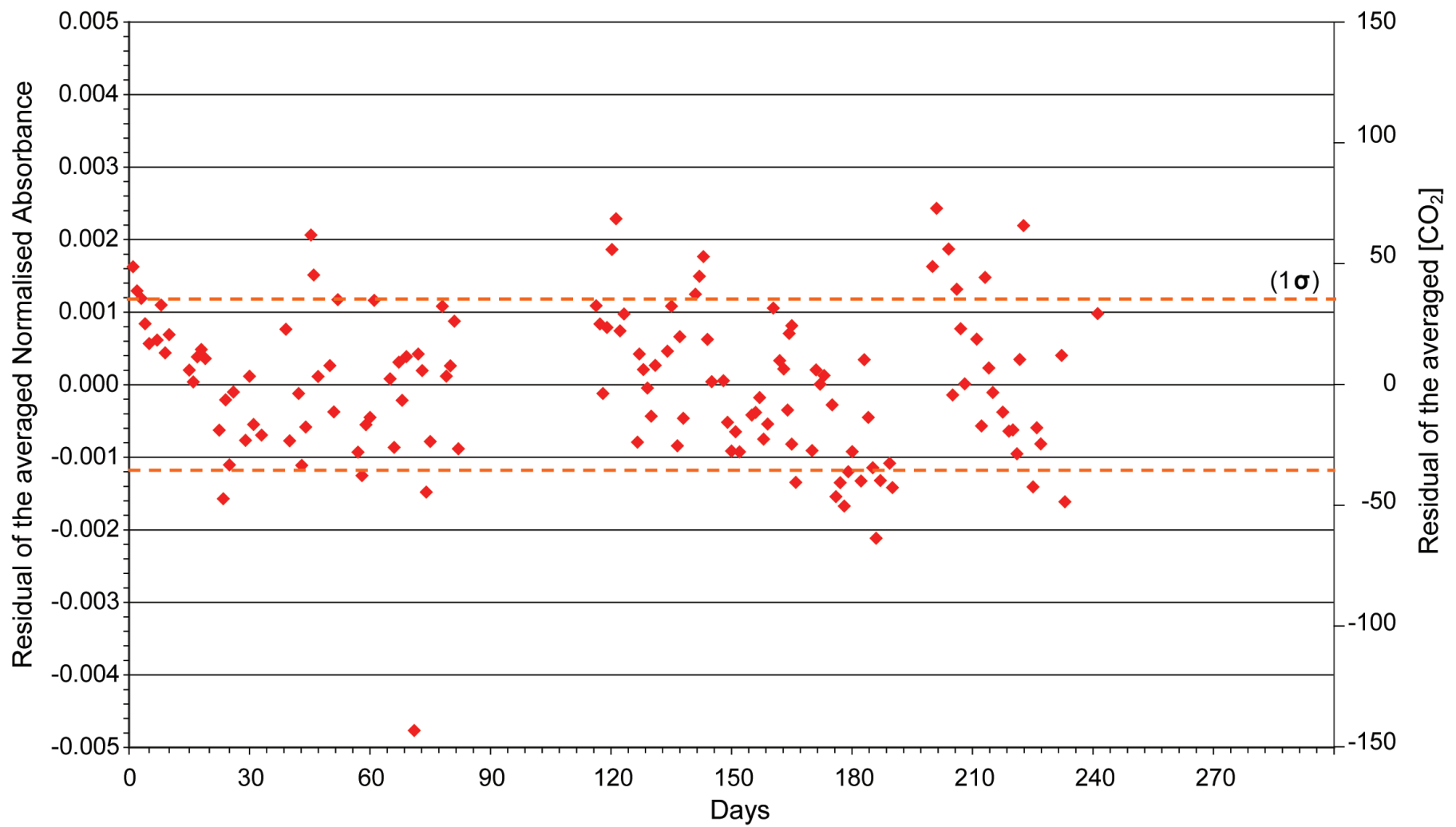

Fig. 4. Deviation from the mean normalised absorbance after correcting for temperature and pressure. The data was measured at roughly daily intervals using a $1832 \pm 40$ ppmv $_{\text {satp }}$ reference gas over a period of eight months (CORA-\#3). 


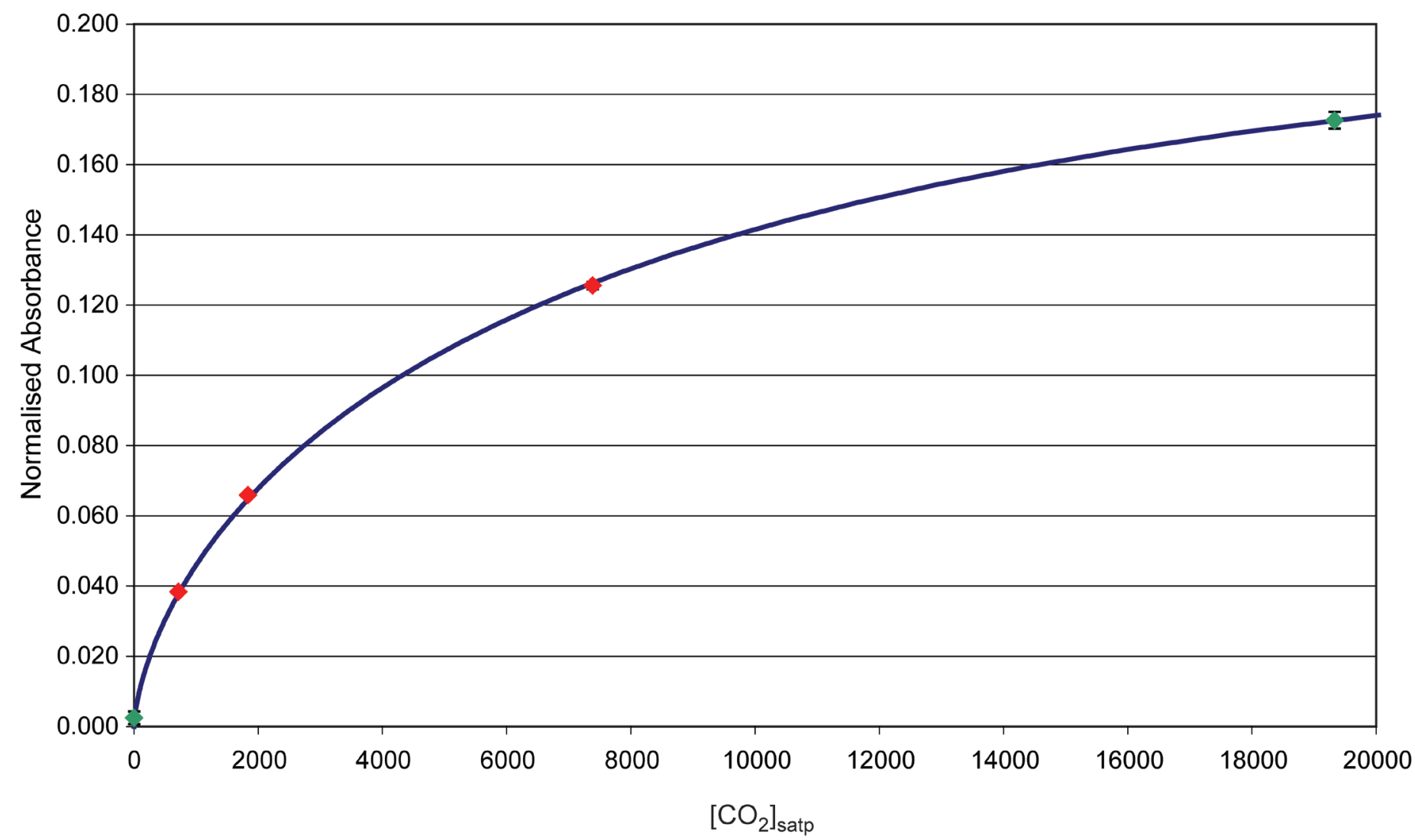

Fig. 5. $\left[\mathrm{CO}_{2}\right]$ values obtained using a 2-point calibration curve at 0 and $2 \%$ (green dots). Validation of CORA's accuracy is given by the measurement of three certified reference gases (red dots). Error bars are smaller than the dot size.

\section{Accuracy}

A 2-point calibration at 0 and $2 \% \mathrm{CO}_{2}$ allows converting the measured output signal into concentrations according to Equation (5). Fig. 5 shows an independent validation of this calibration curve by measuring the absorbance of three reference gases at ca. 800,2000 and 8000 ppmv. All measurements were performed in lab conditions (i.e. dry gas samples) and compensated for temperature and pressure changes using the ideal gas law. The results point to a high accuracy of the instrumental output with actual values within $3 \%$ of the predicted concentration.

\section{Reproducibility}

Table 2 shows $\mathrm{CO}_{2}$ concentrations measured using a certified reference gas (i.e. $7384 \pm 147 \mathrm{ppmv}_{\text {satp }}$ ) with 12 independently calibrated CORA devices. Owing to three different sensor generations, a difference is noticed in the normalised absorbance between CORA 2 to 4,10 to 14 and 21 to 26 , respectively. The calculated concentrations, however, are consistent with values varying between 7248 and $7842 \mathrm{ppmv}$ and a mean of $7508 \pm 179$ ppmv. Taking into account the error margins all instruments reproduce within 3\% (1s confidence interval) of the actual $\mathrm{CO}_{2}$ concentration. The variable instrumental precision observed during this reproducibility test is most likely related to the small number of data available for some of the devices and is statistically not significant. Overall, the accuracy of the determined $\left[\mathrm{CO}_{2}\right]$ data is consistent with previous results.

\section{DISCUSSION AND APPLICATION}

The exponential nature of the Beer-Lambert law results in more precise measurements at low $\mathrm{CO}_{2}$ concentrations. Still, empirical adjustments of linearization coefficients are necessary to achieve adequate accuracy. This requires calibration measurements to be carried out using certified reference gases under controlled atmospheric conditions. The validation of the resulting calibration curve is provided by independent measurements at known $\mathrm{CO}_{2}$ concentrations.

Laboratory experiments have shown that the precision $( \pm 0.1 \%$ of the normalised absorbance, i.e. $1829 \pm 29$ ppmv, Fig. 4) and the accuracy ( $\leq \pm 3 \%$, Fig. 5) of CORA measurements are within the manufacturer's specifications for the NDIR sensor in use $(e 2 v, 2008)$. Nonetheless, Fig. 4 underlines a discrepancy between the short and long-term precision which is attributed to fluctuations in the battery voltage. The latter is assumed to impinge on the rate of instrumental selfheating which is corrected for using an independent temperature probe mounted close to the $\mathrm{CO}_{2}$ sensor. For long-term monitoring periods during which batteries are exchanged at regular intervals, the loss of precision has only a small effect. Over a single battery cycle, this may, however, result in a linear trend towards lower $\left[\mathrm{CO}_{2}\right]$. Hardly noticeable at elevated concentrations, the drift becomes significant at $\mathrm{CO}_{2}$ concentrations close to that of the external atmosphere and needs to be compensated for using a linear detrending function. Stabilisation of the 


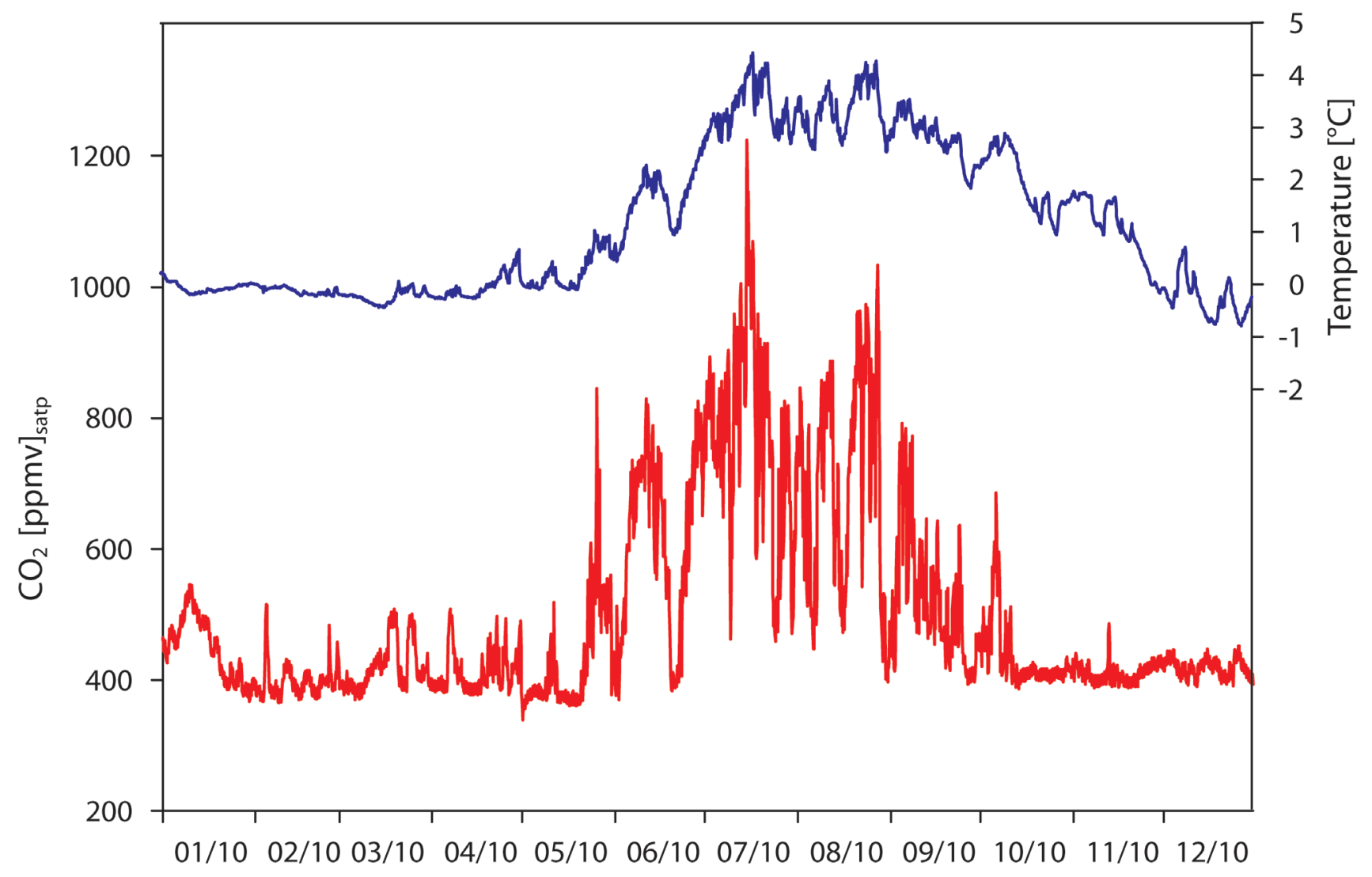

Fig. 6. Example of a $\left[\mathrm{CO}_{2}\right]$ time series of a ventilated alpine cave system obtained using a CORA instrument over a one year monitoring period.

voltage input has been improved in the latest CORA generation.

Although no long-term instrumental drift was observed during the laboratory tests, one instrument (CORA \#11) showed a decreasing trend during field measurements. This linear drift is attributed to a premature aging of the sensor and was not noticed on the other instruments so far. Nonetheless, the drift can be corrected for using a calibration before and after the instrument is deployed in the field.

Because of the remarkable thermal stability of remote cave environments (e.g. Luetscher \& Jeannin, 2004), significant errors associated with temperature effects are not to be expected. Changes in the ambient temperature may, however, impinge on the calibration procedure which relies on a specified reference temperature. Accordingly, attention should be paid to a stable room temperature during extended calibration work.

The carbon dioxide dilution effect due to $\mathrm{H}_{2} \mathrm{O}$-saturated cave atmosphere has been tested empirically by bubbling an 8000 ppmv $\mathrm{CO}_{2}$ reference gas through distilled water until saturation was achieved (CORA \#13). The resultant wet gas yielded a $\mathrm{CO}_{2}$ value lower by $194 \pm 54$ ppmv, i.e. $2.4 \%$ of the calibrated $\left[\mathrm{CO}_{2}\right]$. Even if $\mathrm{CO}_{2}$ dilution associated with natural fluctuations in the cave humidity generally stays within the instrumental precision, the effect has to be accounted for when studying transient ventilation regimes. Similarly, spectral interferences with isotopologues and/or other gas species as well as band-broadening need to be considered when monitoring subtle $\mathrm{CO}_{2}$ changes in poorly ventilated cave chambers with elevated water vapour rates. Although recent developments of laser-based instruments using wavelength-scanned cavity ringdown spectroscopy (WS-CRDS) and off axis integrated cavity output spectroscopy (ICOS) offer promising perspectives for wet sample measurements at high accuracy (Crosson, 2008; Lis et al., 2008), these technologies have not yet been tested extensively in cave environments and still require large power supplies.

For a number of applications, however, such a precise quantification of $\mathrm{CO}_{2}$ concentrations is probably less relevant than the relative fluctuations. Results obtained during laboratory tests show that the specifications of CORA meet typical requirements of karst studies, where the spatial heterogeneity of cave air $\mathrm{PCO}_{2}$ is frequently larger than the instrumental precision (e.g. Baldini et al., 2006).

\section{INITIAL RESULTS FROM FIELD STUDIES}

Fig. 6 shows a one-year record of $\mathrm{CO}_{2}$ concentrations measured at $4 \mathrm{~h}$ intervals in the Milchbach cave system of Switzerland. The logger was installed at $140 \mathrm{~m}$ depth, more than $150 \mathrm{~m}$ from the nearest cave entrance. During the winter season, a cold air flow drawn from the lower entrances cools the cave to sub-freezing temperatures leading to occasional ice formation. Despite this rather harsh 
environment data acquisition ran continuously over the monitoring period. The $\left[\mathrm{CO}_{2}\right]$ time series displays a clear seasonality with peak values measured between June and October synchronous with the maximum of soil productivity above this cave. Daily fluctuations of ca. $25 \mathrm{ppm}$ are observed throughout the record pointing to a well-ventilated cave system subject to forced convection (Luetscher et al., 2011). This highly transient regime directly affects $\mathrm{CO}_{2}$ degassing rates from cave seepage water and thus also impinges on local karstification rates. Quantified mass balances of $\mathrm{CO}_{2}$ exchanges will be presented elsewhere.

\section{CONCLUSIONS}

The CORA monitoring device was specifically developed to monitor carbon dioxide in rough cave environments and has proven to be appropriate for the study of subsurface ventilation regimes. Its small dimensions and low power consumption make it suitable for even remote cave locations. CORA's key strengths include:

A low power consumption allowing for monitoring of at least one annual cycle;

A large measurement range adapted to the analysis of spatially and temporally variable $\mathrm{CO}_{2}$ regimes;

Coupled temperature and pressure probes permitting atmospheric corrections;

A user-friendly software allowing to program measurement intervals and calibration parameters;

A light-weight and robust SD-Card peripheral for safe and convenient data download;

A compact and water-proof case providing protection during demanding cave expeditions.

A two-point calibration using certified reference gases allows for accurate measurements, i.e. \pm 50 ppmv, resp. $\leq \pm 3 \%$ vol. of the measured gas concentration.

Although no significant drift was observed, a regular re-calibration is recommended. CORA's accuracy is sufficient for a wide range of field studies ranging from ventilation to $\mathrm{CO}_{2}$ mass balances in karst environments.

\section{ACKNOWLEDGEMENTS}

The authors are indebted to Christoph Spötl for providing continuous support during the test phase of the device and for constructive comments on an early version of the manuscript. Jiri Faimon, Angel Fernandez-Cortes and Kyle Meyer are acknowledged for their valuable reviews. Partial financial support from SNF (project $\mathrm{n}^{\circ}$ PBZH2-112727) and FWF (project $n^{\circ} 20618$ ) permitted the development of the instrument.

\section{REFERENCES}

Alphasense Ltd, 2009 - NDIR: Origin of Non-Linearity and SPAN. Alphasense application note AAN_204-2 (http://www.alphasense.com/ndir_sensor_notes.html, accessed on 06/12/2011).

Baldini J.U.L., Baldini L.M., McDermott F. \& Clipson N., 2006 - Carbon dioxide sources, sinks, and spatial variability in shallow temperate zone caves: Evidence from Ballynamintra Cave, Ireland. Journal of Cave and Karst Studies, 68: 4-11.

Baldini J.U.L., McDermott F., Hoffmann D.L., Richards D.A. \& Clipson N., 2008 - Very highfrequency and seasonal cave atmosphere $\mathrm{PCO}_{2}$ variability: Implications for stalagmite growth and oxygen isotope-based paleoclimate records. Earth and Planetary Science Letters, 272: 118-129. http://dx.doi.org/10.1016/j.eps1.2008.04.031

Banner J.L., Guilfoyle A., James E.W., Libby A., Stern A. \& Musgrove M., 2007 - Seasonal variations in modern speleothem calcite growth in central Texas, USA. Journal of Sedimentary Research, 77: 615622. http://dx.doi.org/10.2110/jsr.2007.065

Batiot-Guilhe C., Seidel J.L., Jourde H., Hébrard O. $\&$ Bailly-Comte V, 2007 - Seasonal variations of $\mathrm{CO}_{2}$ and ${ }^{222} \mathrm{Rn}$ in a Mediterranean sinkhole - spring (Causse d'Aumelas, SE France). International Journal of Speleology, 36, 51-56.

Bourges F., Mangin A. \& d'Hulst D., 2001 - Carbon dioxide in karst cavity atmosphere dynamics: the example of the Aven d'Orgnac (Ardeche). C. R. Acad. Sci. Paris, Earth and Planetary Sciences 333: 685-692.

Bourges F., Genthon P., Mangin A. \& d'Hulst D., 2006 - Microclimates of l'Aven d'Orgnac and other French limestone caves (Chauvet, Esparros, Marsoulas). International Journal of Climatology, 26: 16511670. http://dx.doi.org/10.1002/joc. 1327

Crosson E.R., 2008. A cavity ring-down analyzer for measuring atmospheric levels of methane, carbon dioxide, and water vapour. Applied Physics B, 92: 403408. http://dx.doi.org/10.1007/s00340-008-3135-y

Cuezva S., Fernandez-Cortes A., Benavente D., Serrano-Ortiz P., Kowalski A.S. \& Sanchez-Moral S. - 2011. Short-term $\mathrm{CO}_{2}(\mathrm{~g})$ exchange between a shallow karstic cavity and the external atmosphere during summer: Role of the surface soil layer. Atmospheric Environment, 45: 1418-1427. http://dx.doi.org/10.1016/j.atmosenv.2010.12.023

Debosz K., Petersen S.O., Kure L.K. \& Ambus P., 2002 - Evaluating effects of sewage sludge and household compost on soil physical, chemical and microbiological properties. Applied Soil Ecology, 19: 237-248. http://dx.doi.org/10.1016/S0929-1393(01)00191-3

Ek C. \& Gewelt M., 1985 - Carbon-dioxide in cave atmospheres - new results in Belgium and comparison with some other countries. Earth Surface Processes and Landforms, 10: 173-187. http://dx.doi.org/10.1002/esp.3290100209

e2v technologies (uk) limited, 2007 - Infrared Sensor Application Note. (http://www.e2v.com, accessed on $06 / 12 / 2011$ ). 
e2v technologies (uk) limited, 2008 - Miniature Infrared Gas Sensors for Hazardous Areas and Intrinsic Safety in Mining (http://www.e2v.com, accessed on $06 / 12 / 2011$ ).

Fairchild I.J., Smith C.L., Baker A., Fuller. L.M., Spötl C., Mattey D. \& McDermott F., 2006 -Modification and preservation of environmental signals in speleothems. Earth-Science Reviews, 75: 105153.

http://dx.doi.org/10.1016/j.earscirev.2005.08.003

Fernandez-Cortes A., Calaforra J.M. \& Sanchez-Martos F., 2006 - Spatiotemporal analysis of air conditions as a tool for the environmental management of a show cave (Cueva del Agua, Spain). Atmospheric Environment, 40: 7378-7394. http://dx.doi.org/10.1016/j.atmosenv.2006.06.045

Fernandez-Cortes A., Sanchez-Moral, S., Cuezva, S., Canaveras, J.C. \& Abella R. 2009. Annual and transient signatures of gas Exchange and transport in the Castanar de Ibor cave (Spain). International Journal of Speleology, 38: 153-162.

Ford D. \& Williams P., 2007 - Karst hydrogeology and geomorphology. Wiley, Chichester, 562p.

Frisia S., Fairchild I.J., Fohlmeister J., Miorandi R., Spötl C. \& Borsato A., 2011 - Carbon mass-balance modelling and carbon isotope exchange processes in dynamic caves. Geochimica et Cosmochimica Acta, 75: 380-400. http://dx.doi.org/10.1016/j.gca.2010.10.021

Halliday W., 1984 - American Caves and Caving. (Revised Edition). Scranton, Pennsylvania: Harpercollins, 348 p.

James J.M., 1977 - Carbon dioxide in the cave atmosphere. Transactions of the British Cave Research Association, 4: 417-429.

Johnson K.R., Hu C., Belshaw N.S. \& Henderson G.M., 2006 - Seasonal trace-element and stable-isotope variations in a Chinese speleothem: The potential for high-resolution paleomonsoon reconstruction. Earth and Planetary Science Letters, 244: 394-407. http://dx.doi.org/10.1016/j.eps1.2006.01.064

Kowalczk A.J. \& Froelich P.N., 2009 - Cave air ventilation and $\mathrm{CO}_{2}$ outgassing by radon-222 modeling: How fast do caves breathe? Earth and Planetary Science Letters, 89: 209-219.

Liñán C., Vadillo I. \& Carrasco F. 2008 - Carbon dioxide concentration in air within the Nerja Cave (Malaga, Andalusia, Spain). International Journal of Speleology, 37: 99-106.

Lis G., Wassenaar L.I:, Hendry M.J., 2008 - HighPrecision Laser Spectroscopy $\mathrm{D} / \mathrm{H}$ and ${ }^{18} \mathrm{O} /{ }^{16} \mathrm{O}$ Measurements of Microliter Natural Water Samples. Analytical Chemistry, 80: 287-293. http://dx.doi.org/10.1021/ac701716q
Luetscher M. \& Jeannin P.-Y., 2004 - Temperature distribution in karst systems: the role of air and water fluxes. Terra Nova, 16: 344-350. http://dx.doi.org/10.1111/j.1365-3121.2004.00572.x

Luetscher M., Hoffmann D., Frisia S. \& Spötl C., 2011 - Holocene glacier history from alpine speleothems, Milchbach cave, Switzerland. Earth and Planetary Science Letters, 302: 95-106. http://dx.doi.org/10.1016/j.epsl.2010.11.042

Mattey D., Lowry D., Duffet J., Fisher R., Hodge E., Frisia S., 2008 - A 53 year seasonally resolved oxygen and carbon isotope record from a modem Gibraltar speleothem: Reconstructed drip water and relationship to local precipitation. Earth and Planetary Science Letters, 269: 80-95.

http://dx.doi.org/10.1016/j.eps1.2008.01.051

Sherwin C. \& Baldini J.U.L., 2011 - Cave air and hydrological controls on prior calcite precipitation and stalagmite growth rates: implications for palaeoclimate reconstructions using speleothems. Geochimica and Cosmochimica Acta, 75: 39153929.

http://dx.doi.org/10.1016/j.gca.2011.04.020

Spötl C., Fairchild I.J. \& Tooth A.F., 2005 - Speleothem deposition in a dynamically ventilated cave, Obir Caves (Austrian Alps). Evidence from modern cave air and drip water monitoring. Geochimica et Cosmochimica Acta, 69: 2451-2468.

Stuart B., 1996 - Modern Infrared Spectroscopy. John Wiley \& Sons, Chichester, 180 p.

Treble P.C., Chappell J. \& Shelley J.M.G., 2005 Complex speleothem growth processes revealed by trace element mapping and scanning electron microscopy of annual layers. Geochimica et Cosmochimica Acta, 69: 4855-4863. http://dx.doi.org/10.1016/j.gca.2005.06.008

Troester J. W. \& White W.B., 1984 - Seasonal Fluctuations in the Carbon Dioxide Partial Pressure in a Cave Atmosphere, Water Resources. Research, 20, 153-156. http://dx.doi.org/10.1029/WR020i001p00153

Wong C.I., Banner J.L. \& Musgrove M., 2011 - Seasonal dripwater $\mathrm{Mg} / \mathrm{Ca}$ and $\mathrm{Sr} / \mathrm{Ca}$ variations driven by cave ventilation: Implications for and modeling of speleothem paleoclimate records. Geochimica and Cosmochimica Acta, 75: 3514-3529. http://dx.doi.org/10.1016/j.gca.2011.03.025 